\title{
Effect of Temperature on Rice Blast Infection Process with Emphasis on Appressoria Formation by Magnaporthe oryzae
}

\section{Laxman Singh Rajput, Taru Sharma, Puchakayala Madhusudhan and Parimal Sinha*}

\author{
Division of Plant Pathology, ICAR-Indian Agricultural Research Institute, \\ New Delhi-110012, India \\ *Corresponding author
}

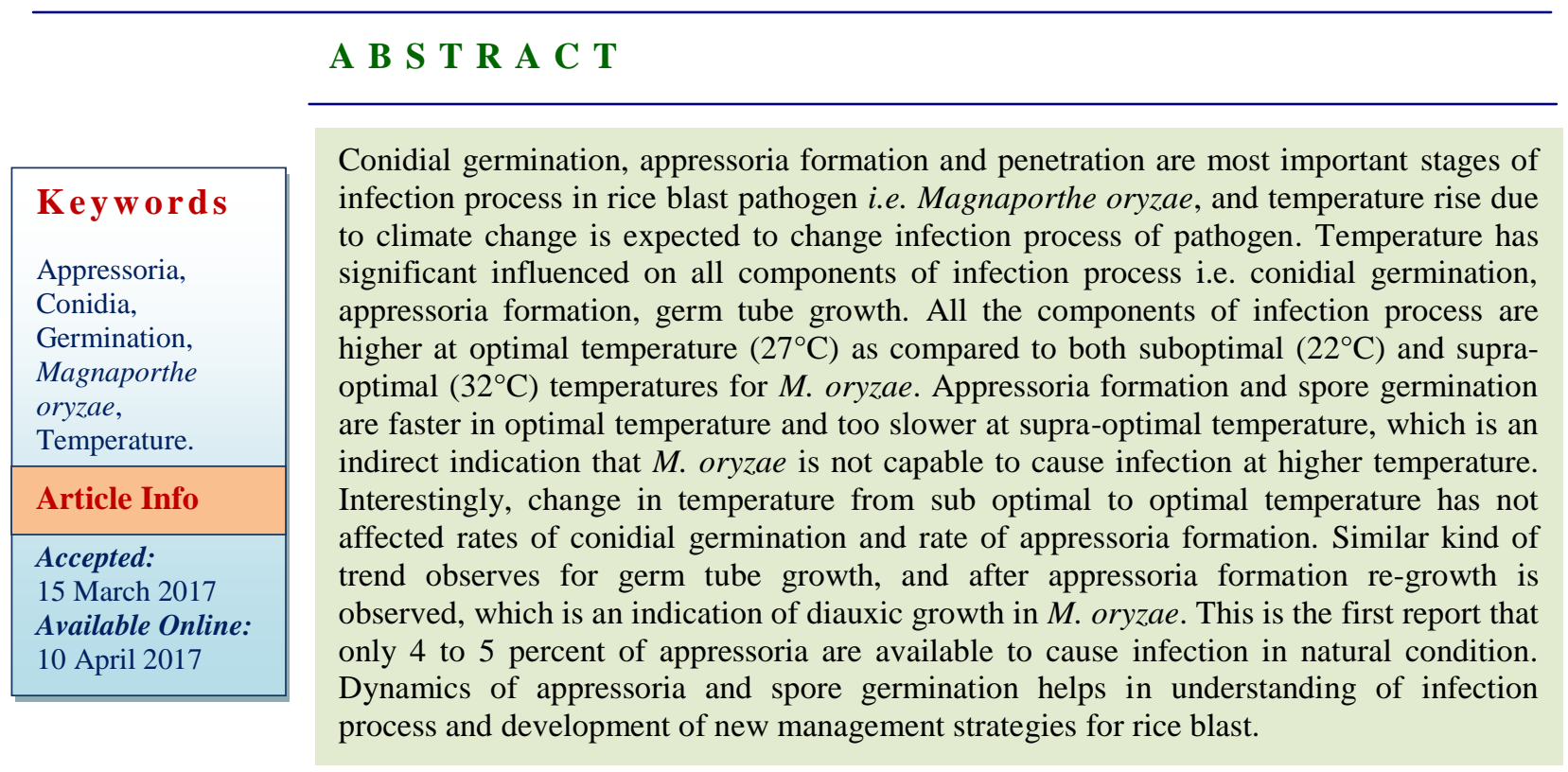

\section{Introduction}

Rice is staple cereal crop for more than half of world population which can provide nearly quarter of total energy intake of human population (FAO, 2014). Magnaporthe oryzae is a causal agent of rice blast, so notorious pathogen among 36 major fungal pathogen reported from rice, having capability to reduce world food grain production by 8 per cent per year (Wilson and Talbot, 2009). Germination of conidial, appressoria formation and penetration are the three most important stages to cause infection in rice by Magnaporthe oryzae. Various pathogens produce appressoria as an infection structures to enter in host plant and establishment of host pathogen interaction (Hamer and Talbott, 1998). M. oryzae conidia after attachment to rice leaves, germinate with a germ tube which can come from any cell of three celled conidia. Germ tube at polar end get differentiated and become swell to form dome shape structure called appressoria, which is after maturation get melanised (Tucker and Talbot, 2001). Various climatic condition influences infection process. Various worker reported a range of temperature for conidial 
germination such as $25-28^{\circ} \mathrm{C}$ (Sueda, 1928; Suzuki, 1969) and $16-32^{\circ} \mathrm{C}$ (Liang, 1979), at same time germination was not observed at low temperature range i.e. $10-15^{\circ} \mathrm{C}$ (Nishikado, 1927). Nearly after 3 hours of host tissues attachment spore germination started in wet condition with $18-38^{\circ} \mathrm{C}$ range of temperature (Kato, 1974). Wide range of temperatures is required for appressoria formation (Suzuki, 1969; Yoshino, 1972; Kato 1974; Rahnema, 1978). Temperature ranges from 21 to $30^{\circ} \mathrm{C}$ is most suitable for formation of appressoria in in vitro conditions (El Refaei, 1977). Germination of conidia is not surface specific while formation of appressoria is very unique to form on particular surface by perceiving of surface singling (Talbot, 2003). Appressorial differentiation is controlled by replication of DNA (Saunders et al., 2010). Mitosis is very essential to form appressoria, it leads to form two daughter nucleuses among which one is migrated into developmental appressorium and second one again return back to conidium (Veneault-Fourrey et al., 2006). Various signalling pathways in appressoria function is dependent on generating high levels of turgor, which results high concentrations of glycerol in appressoria of M. oryzae. Accumulation of glycerol leads to influx of water and lead to generate $8 \mathrm{Mpa}$ hydrostatic pressures. Infection peg is formed due to huge turgor pressures, which enables to $M$. oryzae for forcefully penetrate in plant cuticle and cell wall (Wilson and Talbot, 2009). Global temperature may be rise by $1.5-4.8^{\circ} \mathrm{C}$ by the end of this century (IPCC, 2014); this is substantial challenges for management of plant disease (Coakley and Scherm 1996; Garrett et al., 2006). Change in climatic condition may lead to change in incidence and severity of disease by change in host pathogen interaction (Chakraborty, 2005; Burdon et al., 2006; Eastburn et al., 2011). Optimal temperature conditions for surviving of present species is available in tropical regions while pathogens surviving in cooler climates of higher latitudes required lower temperature; therefore, global warming is expected to their fitness enhance and the rise in epidemics risk of the disease with which they are associated (Ghini et al., 2011). Dynamics of appressoria and spore germination is unknown for the $M$. oryzae under temperature influence that help in understanding the infection process of rice blast and development of new management strategies. Therefore, the aim of this study was to determine the effect of temperature on infection process of $M$. oryzae causing rice blast.

\section{Materials and Methods}

\section{Pathogen growth on artificial media}

To known the effect on infection process of M. oryzae an MJ-24 isolate was grown on rice straw extract dextrose oat meal agar medium (Rice Straw 20g; dextrose 20g; oat meal 20g; agar 20g; biotin 25ng; per litre distilled water), with a mycelial disk $(0.4 \mathrm{~cm})$ at the centre of the Petri-plate and incubated in the BOD incubator (attached with black fluorescent tube of wavelength range of 350$390 \mathrm{~nm}$ ) with cycles $14 \mathrm{~h}$ Near-UV light and $10 \mathrm{~h}$ dark at set of temperatures of $27^{\circ} \mathrm{C}$ (Talbot et al., 1993).

Spore germination, germ tube growth and appressoria formation under set of temperatures

Clean and sterilized glass slides and cover slips (Fixed with sticking agent) were used to study germination and appressoria formation under set of temperatures. Conidia were harvested from 7 days old sporulated culture by scraping with a glass rod in sterile distilled water and adjusted to a concentration of $10^{5}$ spores $/ \mathrm{ml}$. Inside of moist chamber $25 \mu \mathrm{l}$ of spore suspension was kept on glass slides 
covered with cover slips and incubate in BOD at temperature $22^{\circ}, 27^{\circ}$ and $32^{\circ} \mathrm{C}$. Sample was removed at various intervals of $2,4,6,8$, $12,14,20,24,36$ and $48 \mathrm{~h}$ for microscopic observation. Mean of five samples, each containing about 100 conidia was used for comparison. Standard error for samples size was found to be stabilized nearing 94-105 conidia or above.

Rate of Spore germination, rate of germ tube growth and rate of appressoria formation under set of temperatures

Rate of spore germination, rate of germ tube growth and rate of appressoria formation was calculated based on formula $\left(r=\frac{a_{t}-a_{t-1}}{t_{t}-t_{t-1}}\right)$ at different time interval under three temperatures i.e. $22^{\circ}, 27^{\circ}$ and $32^{\circ} \mathrm{C}$. Where $r$ $=$ rate of spore germination; rate of germ tube growth; rate of appressoria formation; $s_{t}$ and $\mathrm{S}_{\mathrm{t}-1}$ was percentage of spore germination; germ tube growth; percentage of appressoria formation at $\mathrm{t}$ and $\mathrm{t}-1$ time. $\mathrm{t}_{\mathrm{t}}$ and $\mathrm{t}_{\mathrm{t}-1}$ was time interval.

Cumulative rate of spore germination, germ tube growth and appressoria formation was calculated based on reciprocal of time taken for $50 \%$ of spore germination, germ tube growth and appressoria formation.

\section{Calculation of appressoria formation}

We assumed that appressoria formation is function of infection and one appressoria was causing one lesion.

If $A f(I)$, than $\frac{d I}{d t}=c \times \frac{d A}{d t}$.

Where A was percentage appressoria, I was percentage infection, $\frac{d A}{d t}$ was rate of appressoria formation, $\frac{d I}{d t}$ was infection rate and $\mathrm{C}$ was a constant.

\section{Results and Discussion}

\section{Selection criteria for selecting of temperatures}

Based on infection ability model developed by Viswanath in 2015 three temperatures were selected for this study i.e., $22^{\circ}, 27^{\circ}$ and $32^{\circ} \mathrm{C}$ (Rajput et al., 2017).

\section{Effect of temperature on spore germination and rate of spore germination in M. oryzae}

Spore germination and rates were affected significantly by temperature (Fig. 1, 2 and Table 1). Spore germination was highest at optimal temperature. Maximum germination 92.5 per cent was observed with in $12 \mathrm{~h}$ of incubation at optimal temperature, while at suboptimal temperature germination of spore was reduced $(81.5 \%)$ and nearly half of spore population can able to germinate at higher temperature $(56.5 \%)$. This indicates that due to higher temperature spore germination was inhibited significantly. The First quarter of spore germination was not significantly affected by suboptimal temperature $(1.9 \mathrm{~h})$ compared to optimal temperature $(1.8 \mathrm{~h})$ but time required for $25 \%$ of spore germination at supra-optimal temperature is very high $(2.8$ h). For second quarter of spore germination same kind of trend observed, but interestingly third quarter of spore germination was affected significantly by all temperature range, meanwhile at supra-optimal temperature $75 \%$ spore was not germinated. This may lead to decrease of disease at supraoptimal temperature. Cumulative rate of spore germination was calculated based on reciprocal of time taken for $50 \%$ of spore germination. At optimal $(0.33 / \mathrm{h})$ and sub optimal $(0.31 / \mathrm{h})$ temperature cumulative rate of spore germination was not affected much by temperature but at supra optimal $(0.19 / \mathrm{h})$ temperature rate of spore germination was reduced by half. It revealed that at optimal 
temperature spore germination is faster and meanwhile maximum population of spore also germinated that leads to cause more infection. Spore germination rates were affected significantly by temperature but interestingly at all temperature it reached highest within 4 hrs. So conclusively, it indicated that spore germination time was less than $4 \mathrm{~h}$. Within the $4 \mathrm{~h}$ maximum spore can be germinated irrespective of temperature.

Similarly, various worker reported a range of temperature for conidial germination such as 25-28 ${ }^{\circ} \mathrm{C}$ (Sueda, 1928; Suzuki, 1969) and 16$32^{\circ} \mathrm{C}$ (Liang, 1979), at same time germination was not observed at low temperature range i.e. $10-15^{\circ} \mathrm{C}$ (Nishikado, 1927). Nearly 3 hours after host tissues attachment germination in spore started in wet condition with $18-38^{\circ} \mathrm{C}$ range of temperature (Kato, 1974).

Effect of temperature on appressoria formation and rate of appressorium formation in $M$. oryzae

Appressoria formation and appressorium formation rates were affected significantly by temperature (Fig. 3 and 4). At optimal and suboptimal temperatures appressoria formation was started with in $4 \mathrm{~h}$ but for supra- optimal temperature, appressoria formation was delayed by $2 \mathrm{~h}$. Both at optimal and suboptimal temperatures, appressorium formation were reached highest within $10 \mathrm{~h}$ i.e. $33 \%$ and $22.5 \%$. After $8 \mathrm{~h}$, appressoria formation was inhibited $(10.5 \%)$ by high temperature.

Immediately after $4 \mathrm{~h}$, appressorium formation rates were reached highest at both optimal and suboptimal temperatures. Cumulative rate of appressoria formation was maximum at optimal temperature $(4.62 / \mathrm{h})$ compare to sub-optimal $(4.07 / \mathrm{h})$ and supra- optimal temperature $(3.5 / \mathrm{h})$.

That indicate appressoria formation is fast in optimal temperature compare to sub-optimal and supra- optimal temperature. Because of that may be pathogen may be able to cause more infection at optimal condition.

At optimal temperature, appressorium formation rate was highest $(5.75 / \mathrm{h})$, compared to suboptimal temperatures $(4.25 / \mathrm{h})$ and supra-optimal temperatures $(2.75 / \mathrm{h})$. At optimal temperature, appressorium formation rate was remain highest for $4 \mathrm{~h}$ to $8 \mathrm{~h}$ and after that slowly decreased, but at suboptimal temperatures immediately after $4 \mathrm{~h}$ it started decreasing. At supra-optimal temperatures appressoria formation rate was got highest at $8 \mathrm{~h}$ and immediate it started decreasing. So conclusively, it indicated that appressorium formation time was varied from 6-8 h, based on temperature.

Various workers reported that wide range of temperatures is required for appressoria formation (Suzuki, 1969; Yoshino, 1972; Kato 1974; Rahnema, 1978). The temperature renge $21-30^{\circ} \mathrm{C}$ is most suitable for formation of appressoria in in vitro conditions (El Refaei, 1977).

Appressoria formation occurs within 4-6 hours when spores are incubated under moist conditions (Rahnema, 1978; Howard et al., 1991).

Appressorium formation and development was regulated by cell cycle in $M$. oryzae, as temperature increases, MgNIMA gene was inhibited which may encodes a protein kinase that was a key factor for mitosis (Osmani et al., 1991).

Interestingly, blocking mitosis may also lead to conidial nuclei degeneration and conidia collapse (Liu et al., 2007). 
Table.1 Time required for each quarter spore germination percentage in $M$. oryzae under temperature influence

\begin{tabular}{|c|c|c|c|c|}
\hline \multirow[b]{2}{*}{$\begin{array}{c}\text { Spore } \\
\text { germination } \\
\text { percentage }(\%)\end{array}$} & \multicolumn{3}{|c|}{ Time required for each quarter spore germination (h) } & \multirow[b]{2}{*}{$\mathrm{CD}(1 \%)$} \\
\hline & $\begin{array}{l}\text { Sub- optimal } \\
\text { temperature } \\
\left(22^{\circ} \mathrm{C}\right)\end{array}$ & $\begin{array}{c}\text { Optimal } \\
\text { temperature } \\
\left(27^{\circ} \mathrm{C}\right)\end{array}$ & $\begin{array}{c}\text { Supra-optimal } \\
\text { temperature } \\
\left(32^{\circ} \mathrm{C}\right)\end{array}$ & \\
\hline 25 & $1.9^{\mathrm{b}}$ & $1.8^{\mathrm{b}}$ & $2.8^{\mathrm{a}}$ & 0.321 \\
\hline 50 & $3.2^{b}$ & $3^{b}$ & $5.4^{\mathrm{a}}$ & 0.543 \\
\hline 75 & $5.7^{\mathrm{a}}$ & $4.5^{\mathrm{b}}$ & 0.0 & 0.573 \\
\hline
\end{tabular}

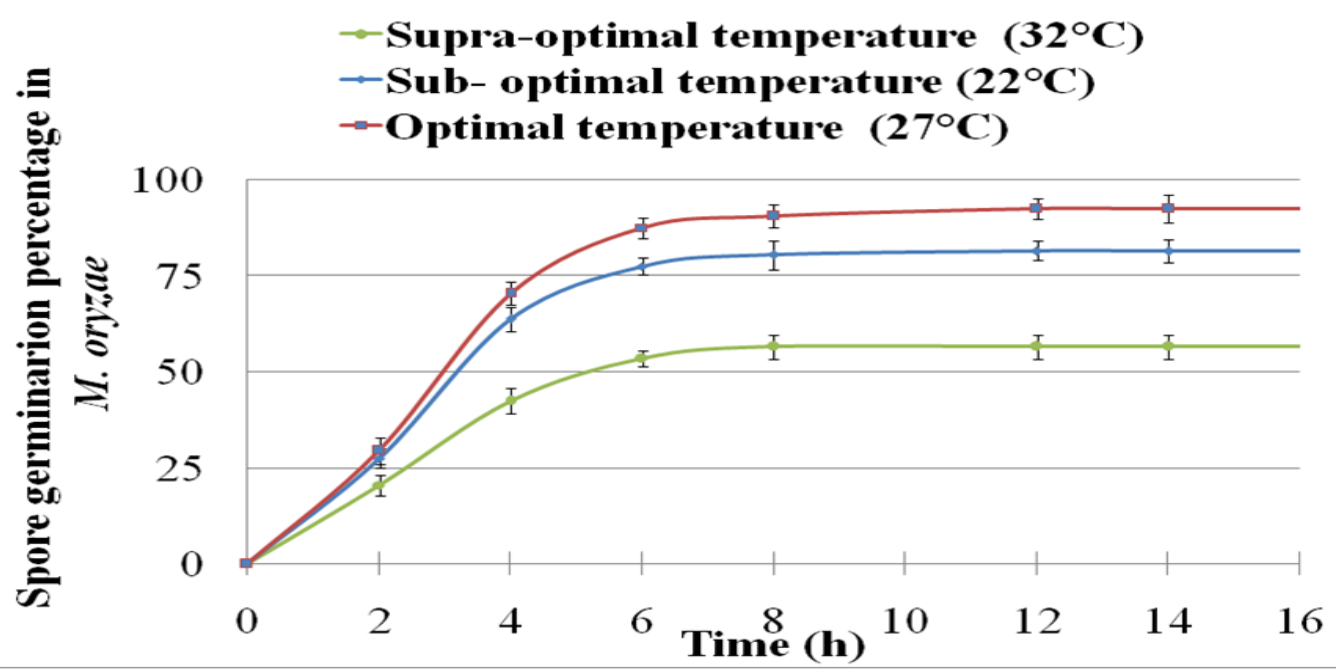

Fig. 1 Spore germination percentage in $M$. oryzae under temperature influence

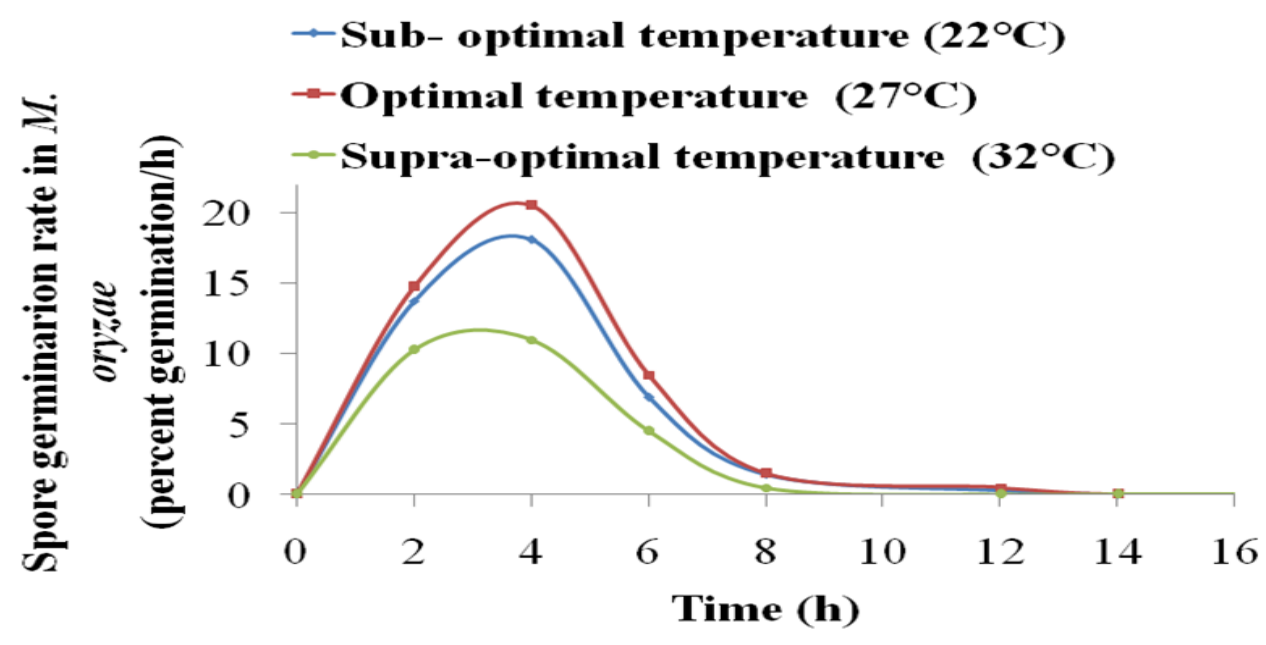

Fig. 2 Spore germination rate in $M$. oryzae under temperature influence 


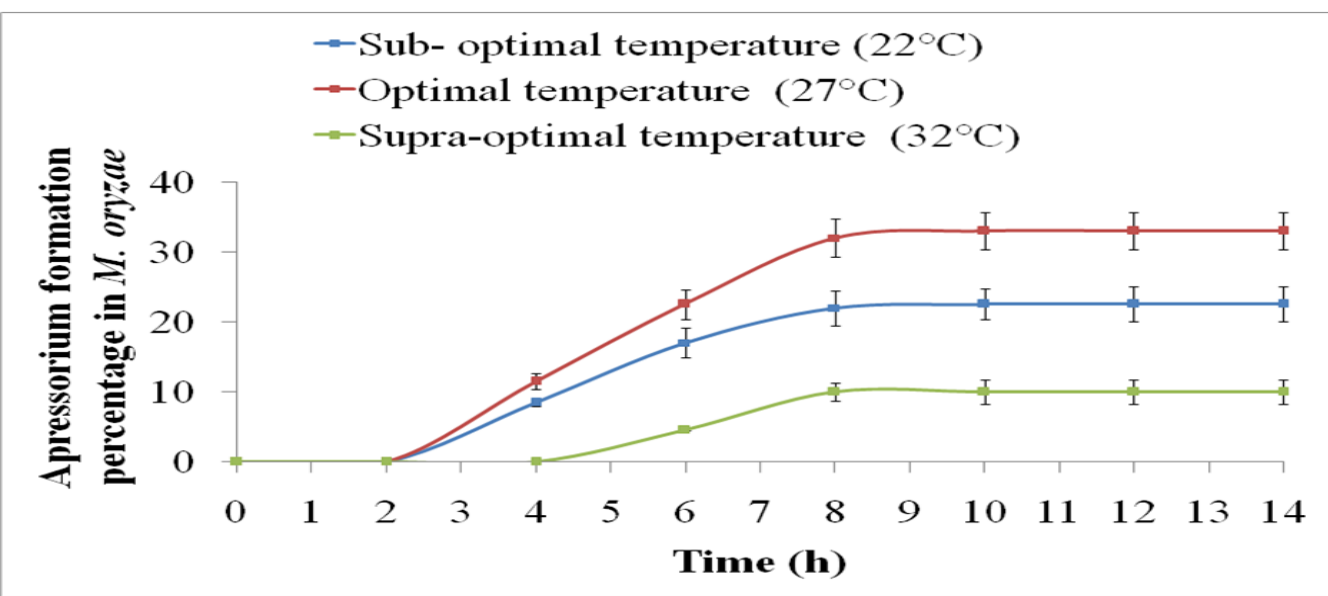

Fig. 3 Appressoria formation percentage in $M$. oryzae under temperature influence

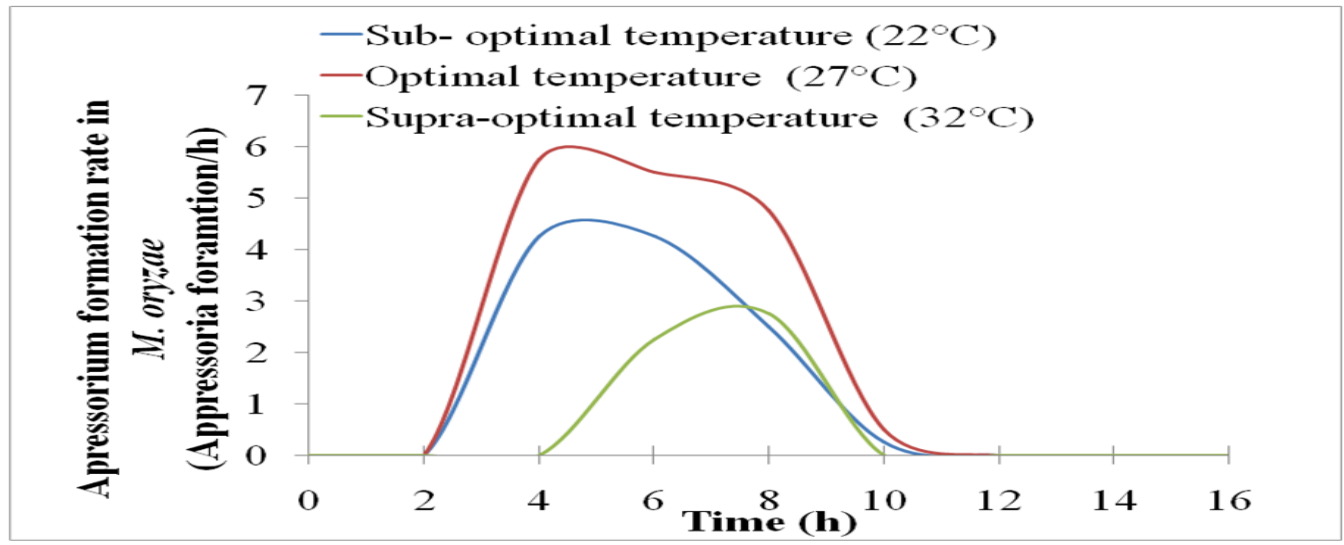

Fig. 4 Dymamics of appressorium formation rate in $M$. oryzae under temperature influence

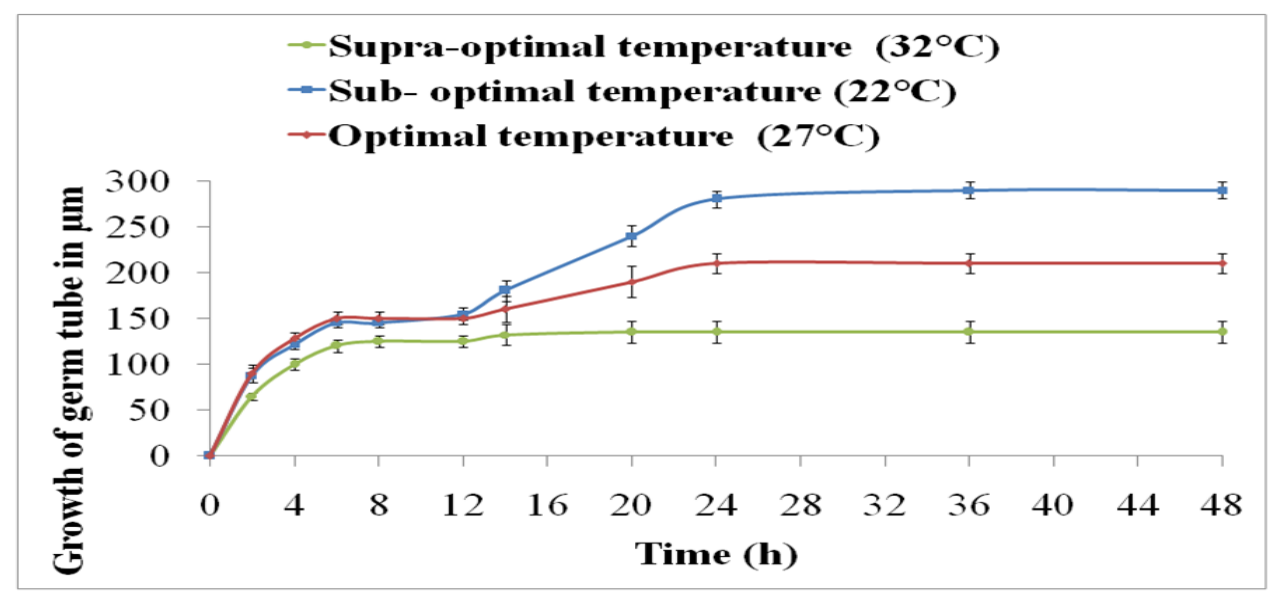

Fig. 5 Germ tube growth ( $\mathrm{mm})$ in $M$. oryzae under temperature influence 


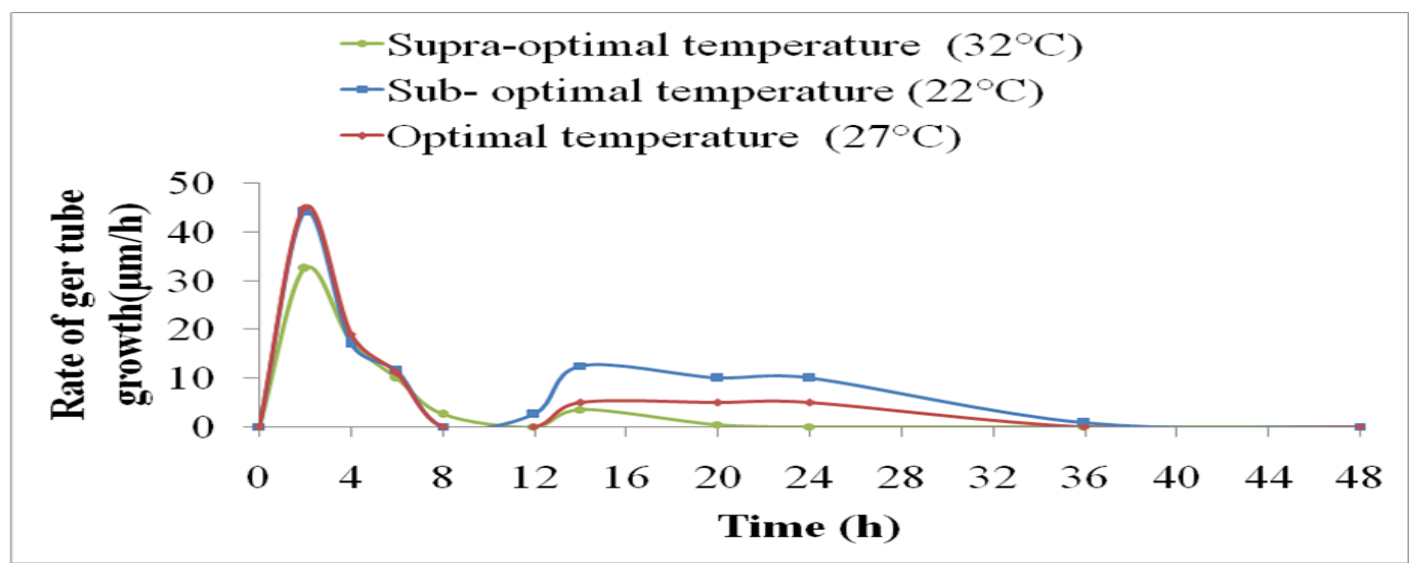

\section{Fig. 6 Germ tube growth rate $(\mu \mathrm{m} / \mathrm{h})$ in $M$. oryzae under temperature influence}

Effect of temperature on germ tube growth and rate of germ tube growth in $M$. oryzae

At all temperatures, spores of $M$. oryzae were grown up to $6 \mathrm{~h}$ and leads to appressoria formation, after a particular time appressoria were again germinated that leads to formation of germ tube (Fig. 5 and 6). At optimal temperature, with in $6 \mathrm{~h}$ germ tubes were grown up to $150.5 \mu \mathrm{m}$, after $12 \mathrm{~h}$ again started grown and up to $24 \mathrm{~h}$ it reached to maximum. Same kind of trend observed at supra-optimal temperature. Fascinatingly at suboptimal temperature, germ tubes were again start growing immediately after $12 \mathrm{~h}(155.5 \mu \mathrm{m})$ and grown rapidly as compared to optimal temperature. Germ tube growth rates were highest before $4 \mathrm{~h}$ at all the temperatures. At optimal and suboptimal temperatures germ tube growth rates were showed similar kind of trend up to $10 \mathrm{~h}$, and reached maximum (45.1 and $44.1 \mu \mathrm{m} / \mathrm{h}$ ). Later on at suboptimal temperature rate was increased significantly up to $38 \mathrm{~h}$ as compared to optimal temperatures (36 h). Similarly $1000 \mu \mathrm{m}$ germ tube growth was reported before differentiate into the unicellular appressorium in $M$. oryzae in rice plant (Howard et al., 1991). Deposition of melanin was observed at each junction, which indicated that melanisation process may be started without appressoria formation.
Recent experiment on Colletotrichum graminicola has shown that if melanin biosynthesis was inhibited than also pathogen could able to the penetration in leaves Meanwhile cell collapse assays showed that melanin was not required for turgour pressure in C. graminicola (Ludwig et al., 2014). This indicated that osmolytes barrier was not provided by melanin in $C$. graminicola, may be same way it does in M. oryzae but melanin plays crucial role in rupture of cell wall (Ludwig et al., 2014).

\section{Effect of temperature on survival of appressoria}

Estimation of rate of appressoria formation on plant is difficult so we assumed that appressoria formation was function of infection rate and one appressoria form one lesion. According to given formula we calculated that $\mathrm{C}$ value, which indicated the percent of appressoria survival on plant. Calculated C value was 0.05 for optimal temperature and 0.04 for both supra-optimal and sub optimal condition. That indicate only 4 to 5 per cent of appressoria can survive in a temperature range from $22^{\circ} \mathrm{C}$ to $32^{\circ} \mathrm{C}$ in natural condition. Main reason behind this was a signal transduction or PAMP triggered immunity of host surface that ultimately leads 
the pathogen to invade the host tissue (Garrett et al., 2006). For pathogen's signal transduction, MAP kinase activity has been found to be indispensable for expression of virulence or aggressivity. Disease progress is controlled by many pathogenicity determinants, encoded by pathogenicity genes. Pathogenicity is a multifaceted process, involves ability of fungus to disturb host metabolism and dispersion of infective spores to host plants (Talbot et al., 1993).

\section{Acknowledgements}

We are very much thankful to NICRA, ICARIndian Agricultural Research Institute, New Delhi-110012, India for providing financial assistance.

\section{References}

Burdon, J.J., P.H. Thrall and Ericson, A.L. 2006. The current and future dynamics of disease in plant communities. Annual Rev. Phytopathol., 44: 19-39.

Chakraborty, S. 2005. Potential impact of climate change on plant-pathogen interactions. Australasian Plant Pathol., 34: 443-448.

Coakley, S.M. and Scherm, H. 1996. Plant disease in a changing global environment. Aspects of Appl. Biol., 45: 227-238.

Eastburn, D.M., A.J. McElrone and Bilgin, D.D. 2011. Influence of atmospheric and climatic change on plant-pathogen interactions. Plant Pathol., 60(1): 54-69.

El Refaei, M.I. 1977. Epidemiology of rice blast disease in tropics with special reference to the leaf wetness in relation to disease development. Ph.D. Thesis. Indian Agricultural Research Institute, New Delhi, India.

FAO. 2014. http://faostat.fao.org/ site/567/ default.aspx\#ancor.

Garrett, K.A., S.P. Dendy, E.E. Frank, M.N. Rouse and Travers, S.E. 2006. Climate change effects on plant disease: Genomes to Ecosystems. Annual Review of Phytopathol., 44: 489-509.

Ghini, R., W. Bettiol and Hamada, E. 2011. Diseases in tropical and plantation crops as affected by climate changes: Current Knowledge and perspectives. Plant Pathol., 60: 100-112.

Hamer, J.E. and Talbott, N.J. 1998. Infection related development in the rice blast fungus Magnaporthe grisea. Curr. Opinion in Microbiol., 1: 693-697.

Howard, R.J., M.A. Ferrari, D.H. Roach and Money, N.P. 1991. Penetration of hard substrates by a fungus employing enormous turgor pressures. Proceedings of the National Academy of Sciences, 88: 11281-11284.

IPCC. 2014. IPCC-II-Intergovernmental Panel on Climate Change. Impacts, adaptation, and vulnerability. Part A: Global and sectoral aspects. Contribution of Working Group II to the $5^{\text {th }}$ Assessment Report of the IPCC. Cambridge University Press, Cambridge.

Kato, H. 1974. Epidemiology of rice blast disease. Rev. Plant Protection Res., 7: 120.

Liang, W.J. 1979. Effects of meteorological factors on spore germination, appressorium formation and invasion of the rice blast fungus Pyricularia oryzae. Nat. Sci. Council Monthl., 7: 810-819.

Liu, X.H., L. Jian-Ping, Z. Lei, D. Bo, M. Hang and Lin, F. 2007. Involvement of a Magnaporthe grisea serine/threonine kinase gene, MgATG1, in appressorium turgor and pathogenesis. Eukaryotic Cell, 6: 997-1005.

Ludwig, N., M. Lohrer, M. Hempel, S. Mathea, I. Schliebner, M. Menzel, A. Kiesow, U. Schaffrath, H.B. Deising and Horbach, R. 2014. Melanin is not required for turgor generation but enhances cell-wall rigidity in appressoria of the corn pathogen Colletotrichum graminicola. Mol. PlantMicrobe Interection, 27: 315-327.

Nisikado, Y. 1927. Studies on rice blast disease. Japan J. Bot., 3: 239-244.

Osmani, A.H., K. O’Donnell, R.T. Pu and 
Osmani, S.A. 1991. Activation of the nimA protein kinase plays a unique role during mitosis that cannot be bypassed by absence of the bimE checkpoint. European Mol. Biol. Organization J., 10: 2669-2679.

Rahnema, I. 1978. Simulation of the effect of different water regime on germination and formation of appressoria of Pyricularia oryzae. J. Plant Dis. Protection, 86: 315-219.

Rajput, L.S., T. Sharma, P. Madhusudhan and Sinha, P. 2017. Effect of Temperature on Growth and Sporulation of Rice Leaf Blast Pathogen Magnaporthe oryzae. Int. J. Curr. Microbiol. Appl. Sci., 6(3): 394401.

Saunders, G.O, Y.F. Dagdas and Talbot, N.J. 2010. Spatial uncoupling of mitosis and cytokinesis during appressoriummediated plant infection by the rice blast fungus Magnaporthe oryzae. Plant Cell, 22: 2417-2428.

Sueda, H. 1928. Studies on the rice blast disease. Report of the Department of Agriculture Government Research Institute of Formosa, 36: 1-130.

Suzuki, H. 1969. Effect of temperature on germination of conidia and appressorium formation of Pyricularia oryzae. Annual
Report of Plant Protection in North Japan, 17: 6-9.

Talbot, N.J. 2003. On the trail of a cereal killer: exploring the biology of Magnaporthe grisea. Annual Rev. Microbiol., 57: 177202.

Talbot, N.J., D.J. Ebbole and Hamer, J.E. 1993. Identification and characterization of $M P G 1$, a gene involved in pathogenicity from the rice blast fungus Magnaporthe grisea. Plant Cell, 5: 1575-1590.

Tucker, S.L. and Talbott, N.J. 2001. Surface attachment and pre-penetration stage development by plant pathogenic fungi. Annual Rev. Phytopathol., 39: 385-417.

Veneault-Fourrey, C., M. Barooah, M. Egan, G. Wakley and Talbot, N.J. 2006. Autophagic fungal cell death is necessary for infection by the rice blast fungus. Sci., 312: 580-583.

Wilson, R.A. and Talbot, N.J. 2009. Under pressure: investigating the biology of plant infection by Magnaporthe oryzae. Nature Rev. Microbiol., 7: 185-195.

Yoshino, R. 1972. Influence of temperature on the incubation period of Pyricularia oryzae and early detection on lesions by staining with iodine potassium iodide. Rev. Plant Protection Res., 5: 105-107.

\section{How to cite this article:}

Laxman Singh Rajput, Taru Sharma, Puchakayala Madhusudhan and Parimal Sinha. 2017. Effect of Temperature on Rice Blast Infection Process with Emphasis on Appressoria Formation by Magnaporthe oryzae. Int.J.Curr.Microbiol.App.Sci. 6(4): 1931-1939. doi: https://doi.org/10.20546/ijcmas.2017.604.229 